\title{
MEDIAÇÃO DE CONFLITOS, DEMOCRACIA PARTICIPATIVA E COMPORTAMENTO CIDADÃO
}

\author{
Jéssica Gomes Dias ${ }^{1}$
}

\section{RESUMO}

O presente trabalho tem o objetivo de apresentar informações sobre o instituto da mediação, bem como suscitar reflexões acerca do comportamento cidadão que esta busca incentivar, bem como sua relação com a democracia participativa. Para tanto, é feita revisão bibliográfica acerca da matéria, utilizando-se autores como Habermas, Young e José Murilo de Carvalho, a fim de contextualizar a mediação de conflitos no panorama da democracia participativa, deliberativa e no modelo de formação da cidadania brasileira. Para que entendamos o demandismo, que tanto enche os tribunais de processos e faz com que o Estado fomente métodos autocompositivos de resolução de conflitos, temos que refletir acerca do nosso modelo de comportamento cidadão, a fim de que a mediação deconflitos seja de fato um instrumento eficaz e justo de resolução de demandas, promovendo comportamento mais consciente, ativo e autônomo do indivíduo perante o judiciário brasileiro.

Palavras-chave: Mediação de conflitos. Democracia participativa. Comportamento cidadão.

\section{ABSTRACT}

The present work has the objective of presenting information about the mediation institute, as well as raising reflections on the citizen behavior that this seeks to encourage, as well as its relation with participatory democracy. In order to do so, a bibliographical review on the subject is made, using authors such as Habermas, Young and José Murilo de Carvalho, in order to contextualize the mediation of conflicts in the overview of participatory, deliberative democracy and in the Brazilian citizenship model. In order for us to understand the large number of proceedings, which both fills process courts and causes the State to boost self-contained methods of conflict resolution, we must reflect on our model of citizen behavior. We have to do it to understand how the conflict mediation can be an effective and fair instrument of resolution of demands, promoting more conscious, active and autonomous behavior of the individual before the Brazilian judiciary.

Keywords: Mediation of conflicts. Participatory democracy. Citizen behavior.

${ }^{1}$ Mestranda em Ciências Sociais - Universidade Federal de Juiz de Fora. 


\section{Introdução}

A mediação de conflitos é um mecanismo de resolução consensual de conflitos adotado pelo Brasil e institucionalizado pelo Conselho Nacional de Justiça(CNJ) por meio da Resolução n¹25/2010, que estabelece uma política pública de tratamento adequado dos problemas jurídicos e conflitos de interesses. $\bigcirc$ CNJ explicita ainda, no artigo $8^{\circ}$ da Resolução, a criação pelos tribunais dos Centros Judiciários de Solução de Conflitos e Cidadania(CEJUSC), o que mostra que a conciliação e a mediação são vistas como formas de promoção de um comportamento cidadão. Posteriormente, a mediação foi positivada por lei e consta, atualmente, como uma etapa obrigatória em várias ações judiciais, conforme determina o novo Código de Processo Civil, que entrou em vigor no ano de 2016.

Ao associar a solução de conflitos por meio da mediação e conciliação com a cidadania, o Conselho Nacional propôs um modelo em que é buscado maior acesso à justiça e comportamento ativo das pessoas que estão envolvidas na situação conflituosa. Cabe então reflexão acerca de como a mediação de conflitos pode contribuir para a real construção de um comportamento cidadão e se pode ser vista como um modo de concretizar o ideal de democracia participativa.

\section{O que é a mediação de conflitos e sua relação com a democracia participativa}

A mediação de conflitos é um método autocompositivo em que as partes envolvidas no conflito são auxiliadas pelo mediador, que funciona como um facilitador do diálogo, considerado um catalisador. Na sessão, os envolvidos têm a oportunidade de falar e escutar a outra parte, buscando construir soluções que sejam adequadas à sua realidade. Trata-se de um espaço de deliberação em que é possível argumentar de forma que se chegue a um acordo construído racionalmente e que coloque fim à demanda. Os indivíduos participam efetivamente da construção da determinação judicial a que serão submetidos, já que o juiz ao homologar o acordo faz com que este tenha força de sentença.

Há princípios que regem a mediação, tais como a imparcialidade, informalidade, oralidade, isonomia entre as partes, busca do consenso e boa-fé. No que tange à mediação extrajudicial, esta é realizada antes de o conflito se tornar um processo, ou seja, antes que as partes ingressem no judiciário, sendo que pode ser realizada, 
tomando como exemplo a cidade de Juiz de Fora, em câmaras privadas ou em polos de resolução de conflitos, como o Dialogar, que funciona no escritório escola da Universidade Federal de Juiz de Fora ou o CEJUS(Centro Judiciário de Resolução de Conflitos), que funciona no Fórum da Justiça Estadual. A medicação também pode ser realizada quando há um processo em curso (mediação judicial).

Segundo o Conselho Nacional de Justiça (Resolução 125), a mediação de conflitos é um instrumento efetivo de pacificação social, solução e prevenção de litígios. De acordo com a Lei da mediação (Lei 13.140/15), pode ser mediador extrajudicial qualquer indivíduo capaz que tenha a confiança das partes e seja capacitado para fazer mediação, independentemente de integrar qualquer tipo de conselho, entidade de classe ou associação, ou nele inscrever-se, podendo, inclusive, ser um profissional de qualquer área, não necessariamente formado em Direito e não sendo obrigatória formação superior.

A mediação pode acontecer em vários ambientes e situações como no campo familiar, escolar ou comunitário, por exemplo. Para tanto, o mediador deve ter bom domínio das técnicas de mediação, tais como: escuta ativa, despolarização da linguagem, reforço positivo, recontextualização, geração de opções e projeção para o futuro. Deve ser capaz de criar um ambiente de harmonia e respeito, em que as partes possam expor suas opiniões e chegar a melhor solução para o conflito, devendo também dominar o método de condução das sessões de mediação: abertura da sessão, apresentação às partes do que é mediação, perceber se há disposição dos envolvidos para tal procedimento, controle do tempo das sessões e tempo de fala de cada um e finalmente a elaboração de um acordo. Ressalte-se que tal acordo, se levado à homologação pelo juiz, com a presença dos advogados das partes, tem força de sentença.

Sobre o processo de mediação, que é voluntário, Moore (1998, p.23) coloca que pode ser vista como um prolongamento ou aperfeiçoamento do processo de negociação, que envolve a interferência de terceira parte aceitável e nãoautoritária. Esta pessoa ajuda as partes principais a chegarem de forma voluntária a um acordo mutuamente aceitável das questões em disputa. Os indivíduos envolvidos têm autonomia e liberdade para manifestar suas visões e opiniões, influenciando e participando efetivamente na construção da decisão. De tal forma, a mediação é vista como uma forma democrática e cidadã de resolução de conflitos, conforme ensina Warat (2001,p.88):

Em termos de autonomia, cidadania, democracia e direitos humanos a 
mediação pode ser vista como a sua melhor forma de realização. As práticas sociais de mediação configuram-se em um instrumento de exercício da cidadania, na medida em que educam, facilitam e ajudam a produzir diferenças e a realizar tomadas de decisões, sem a intervenção de terceiros que decidem pelos afetados em um conflito.

A mediação também pode ser analisada sob a ótica de promoção da democracia participativa e do comportamento cidadão. Young (2000) coloca que para o exercício da democracia participativa devem estar presentes os seguintes princípios: publicidade, inclusão, igualdade, exposição pública de razões e opiniões. Todos os afetados pelas decisões devem poder participar em posição de igualdade, expondo livremente suas razões e opiniões. A autora também coloca o princípio da reasonableness, que se refere à capacidade da pessoa de estar aberta a escutar os outros interessados no que tange a explicar porque sua ideia está incorreta ou inadequada. Afirma ainda que a legitimidade normativa de uma decisão democrática está vinculada ao grau de inclusão viabilizado àqueles diretamente afetados por ela e ao fato de terem a oportunidade de exercer influência sobre os resultados. A autora argumenta ainda que o modelo da democracia deliberativa é um meio de concretizar a inclusão e a igualdade políticas. De tal forma, quando é implementado, aumenta a probabilidade de que o processo de produção das decisões democráticas promova a justiça.

Os ensinamentos colocados pela autora podem ser aplicados ao procedimento de mediação de conflitos, em que os indivíduos fazem parte da construção do processo decisório, que se dará por meio da elaboração de um acordo que leve em consideração os interesses de ambas as partes. Na mediação é proporcionado um espaço em que as partes têm voz ativa, podendo opinar e argumentar no que se refere à melhor forma de solucionar o problema.

Acerca do tema, podemos analisar também a mediação de conflitos sob a ótica da noção de Democracia deliberativa exposta por Habermas (1995), que coloca que em uma república os direitos de cidadania são melhor entendidos como liberdades positivas e não só liberdades negativas. As referidas liberdades positivas garantiriam a participação em uma prática comum, em que os cidadãos poderiam se converter em atores políticos responsáveis por uma comunidade formada por pessoas iguais e livres. Isso iria além do controle da população em relação ao Estado e também da articulação entre o Estado e a sociedade. O autor coloca a importância do consenso alcançado argumentativamente. No âmbito da 
mediação de conflitos é exatamente o que acontece: as partes dispõem de um espaço em que podem argumentar e ter sua opinião levada em consideração a fim de que a decisão tomada reflita a igualdade entre as partes e a liberdade de escolha quanto às soluções disponíveis. Habermas ainda expõe que o paradigma da política no sentido de uma autodeterminação cidadã não é o do mercado e sim a do diálogo. Seguindo uma concepção dialógica, (o autor) entende a política como um processo de argumentação racional e persuasão, não baseado exclusivamente na vontade e no poder. Tal processo seria orientado para a consecução de um acordo acerca de uma forma justa e boa ou no mínimo aceitável de ordenar os aspectos da vida referentes às relações sociais ou natureza social das pessoas.

O conceito de política deliberativa então leva em conta a pluralidade de formas de comunicação nas quais a vontade comum pode se formar, mediante o equilíbrio de interesses e compromissos, que se dá com escolhas racionais de meios com respeito a um fim. As negociações no âmbito de tal tipo de política pressupõe a disponibilidade para cooperação e disposição para respeitar as regras do jogo, de forma a se chegar a resultados que possam ser aceitos por todas as partes, ainda que por distintas razões. A legitimação de uma decisão poderia se dar então quando todos aqueles suscetíveis de serem afetados puderem participar discursivamente. No âmbito da mediação de conflitos é o que acontece, já que a decisão não é imposta pelo Poder Judiciário e sim construída pelas partes envolvidas.

\section{Cidadania e papel da mediação}

A cidadania é comumente desdobrada nas seguintes dimensões: direitos civis, políticos e sociais. De acordo com José Murilo de Carvalho (2002, p.10), seria considerado cidadão pleno quem fosse titular dos três direitos, sendo que quem fosse titular de apenas alguns deles seria considerado um cidadão incompleto. Direitos civis envolveriam os direitos fundamentais à vida, à liberdade, à propriedade, à igualdade perante a lei. Desdobram-se na garantia de ir e vir, de escolher o trabalho, de manifestar o pensamento, de organizar-se, de ter respeitada a inviolabilidade do lar e da correspondência, de não ser preso a não ser pela autoridade competente e de acordo com as leis, de não ser condenado sem processo legal regular. Para a garantia de tais direitos, deve haver uma justiça independente, eficiente, barata e acessível a todos, sendo que sua pedra de toque é a liberdade individual. Quanto aos direitos sociais, esses dependeriam 
da existência de uma eficiente máquina administrativa do Poder Executivo, a fim de garantir o direito à educação, trabalho, saúde e outros direitos.

Após o advento da Constituição Federal de 1988 no Brasil, foi aumentada a possibilidade de acesso à justiça, com o fortalecimento das Defensorias Públicas, gratuidade de justiça e implantação dos juizados especiais, em que é possível iniciar um processo sem advogado desde que o valor da causa não ultrapasse vinte salários-mínimos. Tais mecanismos possibilitaram que mais pessoas pudessem ter acesso aos mecanismos estatais de resolução de conflitos, o que influenciou no aumento do número de processos. Hoje em dia o judiciário está lento e os magistrados não conseguem atuar com celeridade, o que interfere na eficácia dos provimentos jurisdicionais e na satisfação da população. Então este seria o panorama ideal para o surgimento de métodos autocompositivos de resolução de conflitos, a fim de que pudesse se dar o acesso à justiça de forma rápida e barata, reduzindo o número de processos. Seria então o acesso à justiça uma forma de efetivação dos direitos civis, que é uma dimensão da cidadania.

A participação na construção das decisões jurisdicionais pode se dar principalmente por meio da transação, ou seja, pela negociação entre os litigantes e a elaboração de acordos. Para tanto, há a atuação de conciliadores e mediadores, que funcionam como pontes para o diálogo. A disposição para dialogar acerca do conflito exige coragem e atividade mental, pois as pessoas raciocinam acerca do contexto conflituoso em que se encontram a fim de chegar a uma solução considerada justa. Há uma saída da zona de conforto por parte dos jurisdicionados, tão acostumados a entregar ao Estado-juiz a resolução de seus problemas, renunciando à administração de seus próprios conflitos. Segundo Warat (2001,p.161):

[...] Chegou a hora de devolver à cidadania e aos Direitos Humanos suas possibilidades de humanizar nossa relação com os outros, principalmente, por intermédio de um Direito comprometido com a humanização de suas funções nos conflitos, o Direito da mediação.

A mediação promove de fato uma humanização na resolução dos conflitos, pois aproxima o cidadão do processo de resolução de conflitos, tornando-o responsável por suas próprias decisões, visto que serão por ele construídas, e não por um juiz, que muitas vezes não tem a oportunidade de se aprofundar no caso de forma a proporcionar a melhor solução para as partes, sendo que o caso 
muitas vezes envolve meandros psicológicos e sociais. Na grande maioria das vezes, o conflito não é jurídico, mas envolve problemas de relacionamento entre as pessoas. De tal forma, o acesso a decisões justas não pode se restringir ao provimento jurisdicional, sendo que outros meios também devem ser utilizados. Kazuo Watanabe(1988, p.128), que aborda o tema com muita propriedade, estabelece que a problemática do acesso à Justiça não pode ser estudada nos acanhados limites dos órgãos judiciais já existentes. Não se trata apenas de possibilitar o acesso à Justiça enquanto instituição estatal, e sim de viabilizar o acesso à ordem jurídica justa.

Pode-se perceber que Watanabe coloca que o estabelecimento de uma ordem jurídica justa, em que a cidadania é de fato concretizada, transcende os mecanismos formais onde o juiz prolata a sentença e as partes não têm espaço de deliberação. As instituições tradicionais já não são suficientes, sendo a sua morosidade ineficaz perante as demandas da sociedade. No Brasil, principalmente após o advento da Constituição de 1988, que estabeleceu mecanismos mais baratos de acesso à justiça, como os Juizados Especiais e a Gratuidade de Justiça, foi estabelecida uma cultura do demandismo, em que as pessoas se acostumaram a entregar ao poder judiciário a solução dos próprios problemas, desacostumando-se a buscar o diálogo, a negociação e uma efetiva participação na construção da decisão. O acesso à justiça faz parte da dimensão dos direitos civis da cidadania. Isto é certo. Mas a entrega de todos os conflitos para serem resolvidos pelo Estado não é um comportamento cidadão, pois denota falta de autonomia, de participação, de mobilização e extrema dependência do Estado. Para que entendamos o porquê do demandismo, algumas reflexões de José Murilo de Carvalho, acerca da formação da cidadania no Brasil podem ser úteis:

O autor que desenvolveu a distinção entre as várias dimensões da cidadania, T. A. Marshall, sugeriu também que ela, a cidadania, se desenvolveu na Inglaterra com muita lentidão. Primeiro vieram os direitos civis, no século XVIII. Depois, no século XIX, surgiram os direitos políticos. Finalmente, os direitos sociais foram conquistados no século XX. Segundo ele, não se trata de seqüência apenas cronológica: ela é também lógica. (...)Há, no entanto, uma exceção na seqüência de direitos, anotada pelo próprio Marshall. Tratase da educação popular. Ela é definida como direito social mas tem sido historicamente um pré-requisito para a expansão dos outros direitos. Nos países em que a cidadania se desenvolveu com mais rapidez, inclusive na 
Inglaterra, por uma razão ou outra a educação popular foi introduzida. Foi ela que permitiu às pessoas tomarem conhecimento de seus direitos e se organizarem para lutar por eles. A ausência de uma população educada tem sido sempre um dos principais obstáculos à construção da cidadania civil e política.(Carvalho, 2012,p.10-11)

No Brasil, segundo o autor, a cidadania teria se dado de uma forma bem diferente, não se aplicando o modelo Inglês em razão de duas diferenças:

a) há maior ênfase nos direitos sociais, em detrimento dos outros.

b) Houve alteração na sequência em que os direitos foram adquiridos, sendo que aqui os direitos sociais precederam os outros.

Tal alteração na lógica em que se deram as dimensões da cidadania teria o condão de alterar a sua natureza. $\bigcirc$ autor ainda prossegue ensinando que a natureza histórica da cidadania é que ela se desenvolveu dentro do fenômeno histórico chamado Estado-nação, advindo da Revolução Francesa. Lá houve uma luta política nacional, sendo que o cidadão que surgia daí era também nacional, visto que as pessoas se tornavam cidadãs quando passavam a se sentir parte de uma nação e Estado. Para o autor, a cidadania como é conhecida por nós faz parte da lealdade a um Estado e a identificação com uma nação. Para ele, em geral, a identidade nacional se deve a fatores como religião, língua e, sobretudo, lutas e guerras contra inimigos comuns. No Brasil, tal construção de identidade nacional começou a se dar tardiamente após a Guerra do Paraguai:

A forma mais intensa de envolvimento, no entanto, foi a que se deu durante a guerra contra o Paraguai. As guerras são fatores importantes na criação de identidades nacionais. A do Paraguai teve sem dúvida este efeito. Para muitos brasileiros, a idéia de pátria não tinha materialidade, mesmo após a independência. Vimos que existiam no máximo identidades regionais. A guerra veio alterar a situação. De repente havia um estrangeiro inimigo que, por oposição, gerava o sentimento de identidade brasileira. São abundantes as indicações do surgimento dessa nova identidade, mesmo que ainda em esboço. Podem-se mencionar a apresentação de milhares de voluntários no início da guerra, a valorização do hino e da bandeira, as canções e poesias populares (Carvalho, 2002, p.37-38).

A formação de uma identidade nacional, que teve sua semente plantada na 
Guerra do Paraguai, foi marcada pelo movimento de 1930 e pelas campanhas nacionalistas da década de 1950, sobretudo a da defesa do monopólio do petróleo pelo Estado. O nacionalismo, incentivado pelo Estado Novo, foi o principal instrumento utilizado para promover a solidariedade nacional, acima das lealdades estaduais. Também houve uma onda de nacionalismo quando o Brasil conquistou a Copa do Mundo no México (tricampeonato mundial de futebol), o que motivo de grande exaltação patriótica de que o General Médici se aproveitou para promover a sua própria popularidade.

Para Carvalho, a lealdade ao Estado depende do grau de participação na vida política. A maneira como se formaram os Estados-nação condiciona assim a construção do que é cidadania. Em alguns países, como no Brasil, o Estado teve mais importância e o processo de difusão dos direitos se deu principalmente a partir da ação estatal. Em outros, como na França, ela se deveu mais à ação dos próprios cidadãos. O autor afirma (2002,p. 87) que até o ano de 1930 não havia povo organizado de forma política nem sentimento nacional consolidado. A participação popular, inclusive nos grandes acontecimentos, era limitada a pequenos grupos. A grande maioria do povo tinha com o governo uma relação de distância, de suspeita, quando não de aberto antagonismo. Quando o povo agia politicamente, em geral, o fazia reagindo ao que considerava arbítrio das autoridades, como ocorreu na Revolta da Vacina. Podia-se afirmar que era uma cidadania em negativo, já que vinha das reações populares às atitudes do governo consideradas prejudiciais. Sob a égide do Império ou da República o povo não tinha lugar no sistema político, sendo o Brasil para ele ainda uma realidade abstrata.

Quanto à revolta da vacina, como afirma Carvalho(2002,p.74-75), esta teve origem em 1904, quando Oswaldo Cruz iniciou o combate à varíola por meio da vacina, sendo que uma lei havia tornado a vacinação obrigatória. Então os políticos que se opunham ao governo iniciaram uma campanha de oposição a tal ato, o que foi acompanhado pelos positivistas, os quais afirmaram que a vacina não era segura, que podia causar outras doenças e que o Estado não tinha autoridade para adentrar os lares e forçar as pessoas a aceitarem a vacina. A oposição estendeu-se então às camadas populares, organizadas no Centro das Classes Operárias, de forma que cerca de 15 mil pessoas assinaram listas pedindo ao governo que suspendesse a vacinação. Logo a revolta generalizou-se, sendo que os revoltosos mantiveram a cidade em estado de permanente agitação, recebendo ajuda de militares do Exército também rebelados contra o governo. 
As áreas centrais, mais atingidas pela reforma sanitária que estava sendo feita, e a região do porto tornaram-se redutos dos rebeldes, que bloquearam várias ruas com barricadas. Houve vários danos causados pela multidão incontrolável, como destruição de postes de iluminação e prédios públicos. Também houve destruição de calçamentos e assalto de quartéis. De tal forma, o governo decretou estado de sítio e chamou tropas de outros estados para controlar a situação, havendo vários mortos e feridos, sendo que centenas de pessoas foram presas.

Ressalte-se que a Revolta da Vacina não foi um protesto apenas contra a vacinação, mas também contra reforma urbana, a destruição de casas, a expulsão da população e outras medidas sanitárias que incluíam a proibição de mendigos e cães nas ruas, a proibição de cuspir na rua e nos veículos. Foi uma manifestação que revelou insatisfação em relação ao governo, sendo que nenhum líder exerceu controle sobre a ação popular, revelando alguma consciência de direitos pelos cidadãos, que aceitavam o Estado desde que este não interferisse em sua vida privada e valores. Quando espalhou-se o boato que a vacina seria dada nas coxas ou nádegas das mulheres, houve também uma indignação moral por parte da população, o que contribuiu muito para o crescimento da revolta, vez que o povo não aceitaria tal tipo de violação da initimidade por parte do Estado. Este foi um claro exemplo da cidadania em negativo, ou seja, da resistência frente ao Estado quando a população entendeu que seus direitos tinham sido violados.

Após 1930, houve grande avanço no campo dos direitos sociais. No entanto, no campo dos direitos políticos, somente após 1945 começou a haver mais lisura nas eleições, já que havia muitas fraudes na chamada "República dos coronéis", já que os mandões locais não aceitavam perder as eleições. Também havia o voto de cabresto e os currais eleitorais. A população rural, dependente dos grandes senhores de terra, votava em quem eles determinassem. Não havia autonomia no exercício do direito de votar e a população até negociava seu voto por favores ou valores monetários. Segundo Carvalho (2002,p.88), pela primeira vez, a partir de 1945, o voto popular começou a ter peso. Primeiro, em razão da lisura das eleições. Segundo, por sua crescente extensão, visto que o voto foi estendido a homens e mulheres. Ressalte-se, entretanto, que continuavam excluídos os analfabetos (57\% da população) e os soldados das forças armadas. Este período, marcado pelo que se denominou política populista, terminou em 1964, com o golpe militar. Quanto aos Direitos Civis, durante a ditadura, muitos deles foram suspensos, sobretudo a liberdade de expressão do pensamento e de organização. No que se refere à organização sindical, o regime ditatorial a promoveu, mas o 
fez dentro de um arcabouço corporativo, em estreita vinculação com o Estado. Os "atos institucionais" foram os instrumentos legais para a repressão. Por meio do primeiro ato foram cassados os direitos políticos, pelo período de dez anos, de vários líderes políticos, sindicais e intelectuais e militares.

Quanto ao Ato Institucional de $n^{\circ} 2$ (AI-2), este aboliu a eleição direta para presidente da República, sendo que este era escolhido pelos comandos militares, de acordo com a corrente dominante no alto comando. Tal ato também dissolveu os partidos políticos criados a partir de 1945 e estabeleceu um sistema bipartidário, dentre outras medidas, como restrição ao direito de opinião. No que se refere ao Ato Institucional de n 5 (Al-5), este foi que causou maior impacto nos direitos civis e políticos. $O$ congresso foi fechado e todos os atos decorrentes do Al-5 foram colocados fora da apreciação judicial. No inicio de 1970, foi introduzida a censura previa em jornais, livros e outros meios de comunicação, sendo que não havia liberdade de reunião nem inviolabilidade de domicílio. Havia forte repressão aos direitos civis. No entanto, havia o impulso aos Direitos Sociais, como a criação do o Instituto Nacional de Previdencia Social (INPS), unificação da previdência social, com incorporação dos trabalhadores autônomos e empregadas domésticas à previdência e criação do Fundo de Assistencia Rural (Funrural).

Pode-se perceber que no Brasil houve duros golpes à manifestação cidadã. Os períodos ditatoriais dificultaram muito a organização da população. No que tange ao período do Estado Novo, Carvalho (2002, p. 125-126) diz:

É preciso, portanto, reconhecer que a inversão da ordem dos direitos, colocando os sociais a frente dos políticos, e mais ainda, sacrificando os últimos aos primeiros, não impediu a popularidade de Vargas, para dizer o mínimo. A ênfase nos direitos sociais encontrava terreno fértil na cultura política da população, sobretudo da população pobre dos centros urbanos. (...) O populismo, no Brasil, na Argentina, ou no Peru, implicava uma relação ambígua entre os cidadãos e o governo. Era avanço na cidadania, na medida em que trazia as massas para a política. Mas, em contrapartida, colocava os cidadãos em posição de dependência perante os líderes, aos quais votavam lealdade pessoal pelos benefícios que eles de fato ou supostamente thes tinham distribuído. A antecipação dos direitos sociais fazia com que os direitos não fossem vistos como tais, como independentes da ação do governo, mas como um favor em troca do qual se deviam gratidão e lealdade. A cidadania 
que daí resultava era passiva e receptora antes que ativa e reivindicadora.

Pode-se dizer que essa posição passiva e dependente em relação ao Estado, quanto aos Direitos Sociais, reflete-se no comportamento do cidadão perante o Poder Judiciário, já que as pessoas acabam por assumir um comportamento passivo, à espera de uma sentença que determine a solução para a situação, sem que participem efetivamente, por meio de espaço de fala ou debates acerca da situação conflituosa. Ainda temos, nesse sentido, como expõe José Murilo de Carvalho, uma cidadania passiva e receptora, com uma dependência e relação ao Estado-juiz, o único supostamente capaz de dar fim à demanda e determinar o que é melhor para as partes.

A população só teve a oportunidade de se organizar melhor e de tornar-se mais ativa, no que tange a pleitear direitos, após a segunda metade dos anos 70, com a abertura do governo Geisel, conforme ressalta Carvalho (2002). Tratase de movimento muito recente. Dentre os movimentos que surgiram em tais contextos, destaca-se o movimento dos favelados, cuja tática mais comum era o contato direto com as administrações municipais. Eram pleiteadas melhores condições de vida e infraestrutura, como asfaltamento de ruas, redes de água e de esgoto, energia elétrica, transporte publico, segurança, serviços de saúde e regularização da posse de seus lotes. Houve ainda a expansão de associações de profissionais de classe media, como a de professores, médicos, engenheiros e funcionários públicos, sendo que as associações de classe média, juntamente com os sindicatos, teriam se tornado focos de mobilização profissional e política. O auge da mobilização popular se deu em 1984, com a campanha pelas eleições diretas. Nesta ocasião, a bandeira nacional teria sido recuperada como símbolo cívico, sendo que a última vez em que fora usada publicamente tinha sido nas manifestações de nacionalismo conservador e xenófobo que aconteceram no governo Médici. Pode-se perceber que a inversão das dimensões da cidadania que ocorreu no Brasil trouxe sérios impactos para o comportamento cidadão que aqui foi construído. Os períodos ditatoriais, em que foi dada importância primordial aos direitos sociais, sufocaram, e muito, os direitos políticos e civis. Nossa democratização e a criação de condições para um comportamento cidadão participativo veio tarde e hoje em dia sofremos os efeitos disso. Quanto à participação, no que tange ao poder judiciário, estamos atualmente tendo maior espaço com os movimentos de mediação e conciliação. Mas não há o hábito por grande parte da população brasileira de pleitear as soluções mais favoráveis à 
concretização de direitos. Ainda há a aceitação por grande parte das pessoas das decisões prolatadas pelo Estado. E isso acontece também quanto ao Estado-juiz.

Com a redemocratização e a promulgação da Constituição Federal de 1988, também chamada de "Constituição-cidadã", houve mudanças significativas quanto ao exercício da cidadania. Quanto ao voto, este tornou-se facultativo para os analfabetos, sendo que pessoas com idade a partir de 16 anos já poderiam votar. No que se refere aos direitos sociais, houve uma ampliação, como ressalta Carvalho (2002,p.206), já que fixou-se em um salário-mínimo o limite mínimo para as aposentadorias e pensões e estabeleceu-se que haveria pagamento de pensão de um salário-mínimo a todos os deficientes físicos e a todos os maiores de 65 anos, independentemente de terem contribuído para a previdência. Foi introduzida ainda a licença-paternidade. No que tange aos direitos civis, estes foram recuperados com a redemocratização, sendo que foram criados vários instrumentos para a defesa de direitos, como o Habeas data, mandado de injunção e criação dos juizados especiais, ressaltando-se que esta última medida aumentou consideravelmente o acesso à justiça. $O$ autor ressalta que as inovações legais foram importantes, mas grande parte da população brasileira desconhece seus direitos civis, extensão desses e garantias dele advindas, sendo que o fator mais importante para o conhecimento dos direitos seria a instrução. Interessante a crítica no autor, que ainda continua valendo no panorama atual:

O Judiciário também não cumpre seu papel. O acesso à justiça é limitado a pequena parcela da população. A maioria ou desconhece seus direitos, ou, se os conhece, não tem condições de os fazer valer. Os poucos que dão queixa à polícia têm que enfrentar depois os custos e a demora do processo judicial. Os custos dos serviços de um bom advogado estão além da capacidade da grande maioria da população. Apesar de ser dever constitucional do Estado prestar assistência jurídica gratuita aos pobres, os defensores públicos são em número insuficiente para atender à demanda.

Uma vez instaurado o processo, há o problema da demora. Os tribunais estão sempre sobrecarregados de processos, tanto nas varas cíveis como nas criminais. Uma causa leva anos para ser decidida (Carvalho, 2002,p.214).

Diante deste panorama, torna-se importante o papel dos métodos autocompositivos de resolução de conflitos, visto que proporcionam o acesso à justiça de forma rápida e barata. Mas para que a população tome consciência 
de tais métodos e de sua importância, buscando a negociação e o diálogo para a resolução das demandas, deve comportar-se de forma mais autônoma e independente do Estado-Juiz, tomando para si a responsabilidade no que tange à tomada de decisões e a construção da melhor solução para o conflito.

\section{Considerações Finais}

Entre nós, de forma geral, não há o hábito da negociação e do diálogo buscando um acordo, o que gera um demandismo ao Estado. Pode-se dizer que isso se deve em parte ao tipo de cidadania que foi aqui construído, visto que os direitos sociais, providenciados pelo Estado, vieram antes dos direitos civis e fomos marcados por períodos ditatoriais em que houve forte supressão da manifestação cidadã e da participação da população. Então, não podemos querer que as pessoas tomem consciência de seus direitos e deveres do dia para a noite e resolvam negociar de forma a construir uma decisão, sabendo que o Estado já faz isso por elas. Deve-se perceber, para que o panorama demandista mude, que a resolução de conflitos por parte do Estado não é a única cabível e que o comportamento cidadão, em sua plenitude, demanda participação ativa.

Para que o direito civil de acesso a uma ordem jurídica justa seja concretizado, com a ajuda dos métodos autocompositivos de resolução de conflitos, ainda há que se caminhar. Os jurisdicionados devem ser conscientizados da importância e da utilidade de tais métodos, percebendo sua legitimidade e vantagens no que tange à celeridade. Sem que haja conscientização da população, que pode ser por meio de campanhas, cursos, divulgação, inserção de tópicos acerca de mediação e conciliação nas escolas, dentre outros meios, o comportamento cidadão perante o Poder Judiciário não chegará a sua plenitude, e chegaremos a uma justiça tão abarrotada de processos que se tornará insustentável.

O comportamento cidadão buscado na mediação, que pode ser entendido como a proatividade e responsabilidade na resolução dos próprios conflitos, por meio do diálogo, argumentação e espaço de fala, sem que haja interferência direta do juiz impondo uma decisão, só pode ser alcançado por meio da conscientização e da assunção de uma posição mais autônoma. Com decisões construídas pelas próprias partes, há maior possibilidade de que sejam construídas soluções mais justas e que atendam melhor às necessidades das partes envolvidas, embora existam assimetrias entre elas, que o mediador deve buscar minimizar. Os primeiros passos já estão sendo dados, sendo que temos motivos para sermos 
otimistas quanto à expansão dos métodos autocompositivos impulsionando a cidadania.

\section{Referências bibliográficas:}

Carvalho, José Murilo. Cidadania no Brasil. O longo Caminho. $3^{a}$ ed. Rio de Janeiro: Civilização Brasileira, 2002.

Habermas, Jurgen. Três modelos normativos de democracia. Editora Lua Nova. 1995. Diponível em www.scielo.br/pdf/In/n36/a03n36.pdf.

MOORE Christopher W. O Processo de mediação: estratégias práticas para a resolução de conflitos, tradução Magda França Lopes. Porto Alegre: Artmed, 1998.

WARAT, Luis Alberto. Em nome do acordo. A mediação no Direito. Buenos Aires: Angra Impresiones, 1998.

YOUNG, Iris Marion. “Democracy and justice”. In: YOUNG, Iris Marion. Inclusion and Democracy. New York: Oxford University Press, 2000. e-book.

WATANABE, Kazuo. Acesso à Justiça e Sociedade Moderna. In: Participação e processo. São Paulo: Ed. RT. 1988. p.128. 